\title{
Development of Assessment Methodology for Improving Performance in SME's
}

\author{
Osama Alaskari, M Munir Ahmad \\ School of Science and Engineering, Teesside University, Middlesbrough, UK
}

\begin{abstract}
Purpose - The purpose of this paper is to develop an assessment methodology that can be used to evaluate performance of Small and Medium Enterprises (SMEs) in the manufacturing sector.

Design/methodology/approach - This area of the study focuses on the assessment of performance in manufacturing SMEs. The methodology contains qualitative and quantitative measures that can quantify the opportunities and benefits within SMEs, as well as identifying the performance gaps between the current performance of the company and world class performance. This includes reviewing the literature relating to assessment methodology and collecting data by carrying out semi-structured interviews with staff at target SMEs.
\end{abstract}

Findings - The results show that the proposed assessment methodology is effective in identifying hidden opportunities and benefits in the manufacturing SMEs sector, establishing world class performance of the companies and comparing this with current performance in order to identify gaps in performance in manufacturing SMEs.

Practical implications - This assessment can be used for monitoring and assessing SMEs performance. The developed methodology can be used by manufacturing SMEs as an assessment and benchmarking tool. It enables manufacturing SMEs to identify opportunities for improvement and determine the gaps in current performance; this will assist manufacturing SMEs in selecting an appropriate tool to improve their performance in order to achieve the company objectives.

Originality/value - This paper presents a successful and effective assessment methodology for manufacturing SMEs. It measures current performance which will provide a useful indicator to identify waste. It attempts to improve company performance and suggests how such activities could be organised and managed more effectively. Consequently it leads to a high potential for cost and time saving and quality improvement.

Keywords - Small and Medium Enterprises, performance measurements, assessment Methodology.

Paper type - Research paper

\section{Introduction}

SMEs have received great attention in recent years due to the important role they play in most national economies, in both developed and developing countries. They are perceived as the main drivers of economic growth, product innovation and job creation in the United Kingdom (UK) (Stanworth and Purdy, 2003). The globalisation and growth in markets has led to pressures on companies, including SMEs, and made the level of competition very high. Therefore, the SMEs need to adopt different improvement approaches to remain competitive. There are many approaches available for SMEs which can bring change and make improvement in their performance, such as Lean Tools, Six Sigma, Total Quality Management (TQM) and Enterprise Resource Planning (ERP) systems. Therefore, before implementing any new initiative for improvement, SMEs need to measure and assess their current performance in order to identify the opportunities and select the appropriate techniques for improvement.

The conducted literature review shows that several suggestions have been made with regard to assessment method effectiveness. According to Hudson et al. (2001), although the effect of the assessment methods on large 
companies has been demonstrated comprehensively in existing literature, little attention has been paid to SMEs adopting such methods. In recent years the most important changes have created a favourable context for the implementation of performance measurement systems in SMEs, particularly in the manufacturing sector (Garengo et al., 2005).

In order to contribute to the literature, this paper presents an assessment methodology which can be used in manufacturing SMEs, based on a method developed by Ahmad and Benson (1999). This paper is structured as follows: Firstly, review the literature to identify an assessment methodology. Secondly, a developed methodology that can be used in SMEs with respect to the study aim. The methodology was tested through three cases studies and the results obtained are presented. Finally, discuss and conclude findings, highlighting implications for research and practice. The developed methodology of this paper is beneficial particularly for manufacturing SMEs because the study presents a set of appropriate key performance indicators (KPIs) to measure their performance. In addition, the paper contributes to the literature related to the assessment methodology from the SMEs perspective.

\section{Research methodology}

Two main methods have been employed in this paper: a literature review and a multiple case study of SMEs.

\section{- Literature review}

An initial literature survey was undertaken to establish the status of current knowledge in the area of performance measurement and assessment methodologies.

\section{Performance Measurement in SMEs}

SMEs operate in a high and dynamic turbulent environment (Hudson et al., 2001; Kennerley and Neely, 2003; Cocca and Alberti, 2010; Barrows and Neely, 2011). Therefore, it is important for the SMEs to be able to rapidly change and interpret these changes accurately and to respond to market change appropriately. Thus, several authors have highlighted the significance for all major companies in evaluating and modifying performance measures in order to adapt to the rapidly changing and highly competitive business environment (Eccles, 1991; Kennerley and Neely, 2002).

Currently, the literature presents many models designed for large companies, but these models do not appear to apply very well to SMEs, as they are too multi-staged, focus too much on strategy, long-term and timemoney consuming (See e.g. The strategic measurement analysis and reporting technique (SMART) Lynch and Cross, 1991; balanced scorecard, Kaplan and Norton, 1992; the performance prism, Neely and Kennerley, 2002; the hierarchical performance measurement system, Keegan et al., 1989).

Nudurupati et al, (2011) stated that a number of independent researchers, having examined and explored performance measurement from SMEs perspective, concluded that the majority of performance measurement work, although theoretically valid, does not take into consideration the fundamental differences between SMEs and larger organisations, thus resulting in the poor adoption of performance measurement practices in SMEs. Nevertheless, the most recognised work in performance measurement in SMEs was carried out by Taticchi et al 2010; Taticchi et al 2008; Garengo et al., 2005; Manville, 2006; Chennell et al., 2000; Laitinen, 1996, 2002; Cocca and Alberti, 2010. According to Garengo et al, (2005), in the last 15 years, the eight most widely used performance measurement models are:

1. Performance measurement matrix (Keegan et al., 1989).

2. Performance pyramid system (Lynch and Cross, 1991)

3. Performance measurement system for service industries (Fitzgerald et al., 1991)

4. Balanced Scorecard (Kaplan and Norton, 1992, 1996)

5. Integrated performance measurement system (Bititci et al., 1997) 
6. Performance Prism (Neely et al., 2002).

7. Organisational Performance measurement $\left(\mathrm{OPM}^{\circledR}\right)($ Chennell et al., 2000)

8. Integrated Performance measurement for small firms (IPMS) (Laitinen, 1996, 2002)

Most of these models make no reference to company size, however models 7 and 8 were specifically developed for SMEs, so a brief summary of the two models is explained below:

- Organisational performance measurement was developed specifically for SMEs. In this model, the most important indicator is stakeholder satisfaction. The model starts at strategic level, to determine external measures, followed by a set of key performance indicators at tactical level to enable the prediction and management of organisational performance. At operational level, measures are utilised for monitoring and control and improvement, however, the model is based on three principles: Alignment, i.e. the selected performance measures support the alignment between peoples' actions and company strategy; process thinking, i.e. the measurement system makes reference to the process of monitoring, control and improvement systems; practicability, i.e. at any level in the company, there is a consistent process for identifying measures that should be considered for ensuring the quality and suitability of data.

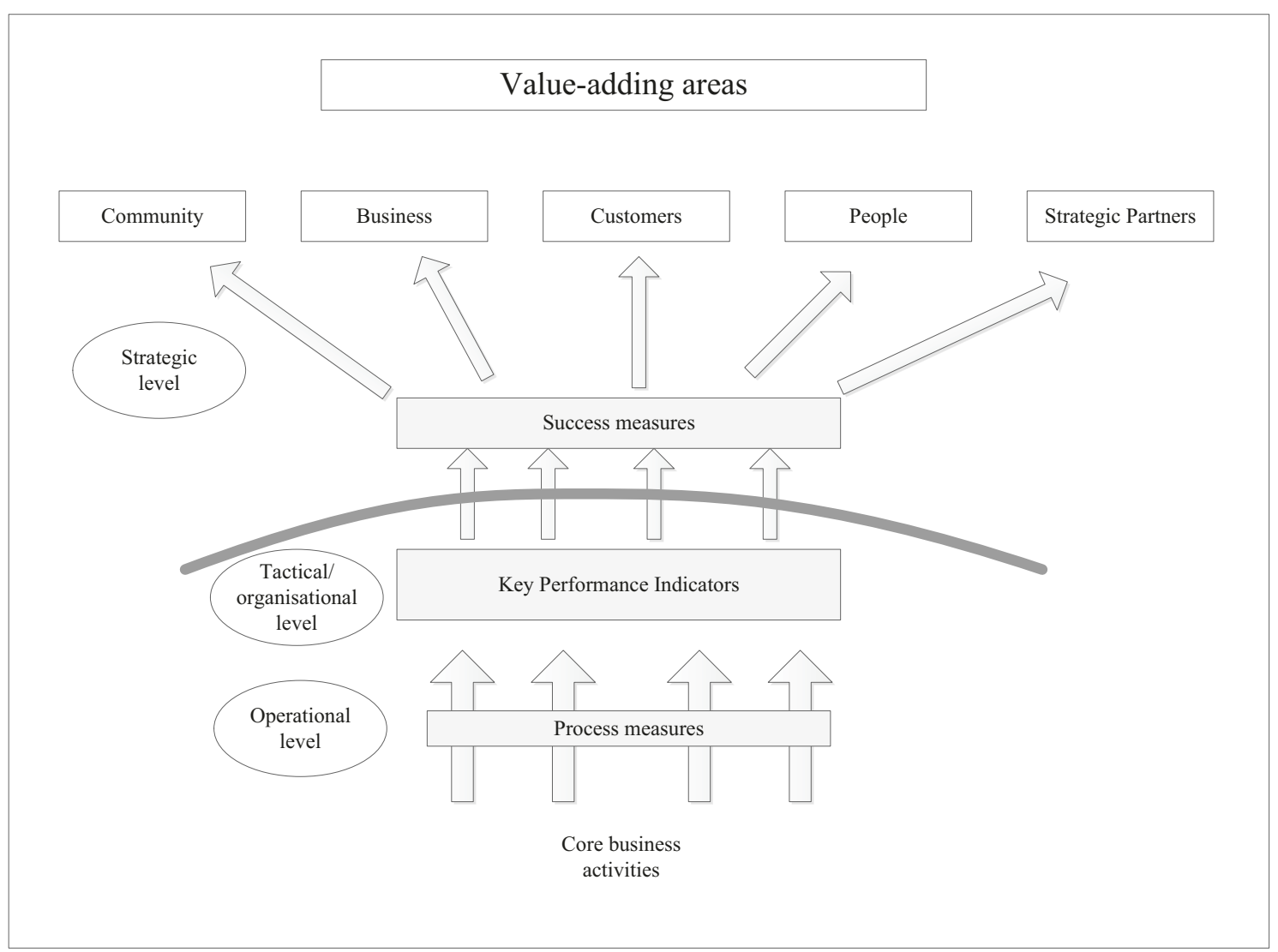

Figure 1. Organisational Performance Measurement Model (Chennell et al., 2000)

- Integrated performance measurement for small firms is specifically designed for SMEs. The aim of this model is to develop a useful managerial tool for measuring and improving performance within the companies. It is based on seven main dimensions of measures categorised into two external dimensions (financial performance and competitiveness), and five internal dimensions (costs, production factors, activities, products and revenues) which are connected by a causal chain. The internal dimensions are used to monitor the whole production process and the external dimensions are used to monitor the company's position in its competitive context. This framework is designed for the exclusive use of the 
director, implying that it is designed only for companies where the top management has complete control.

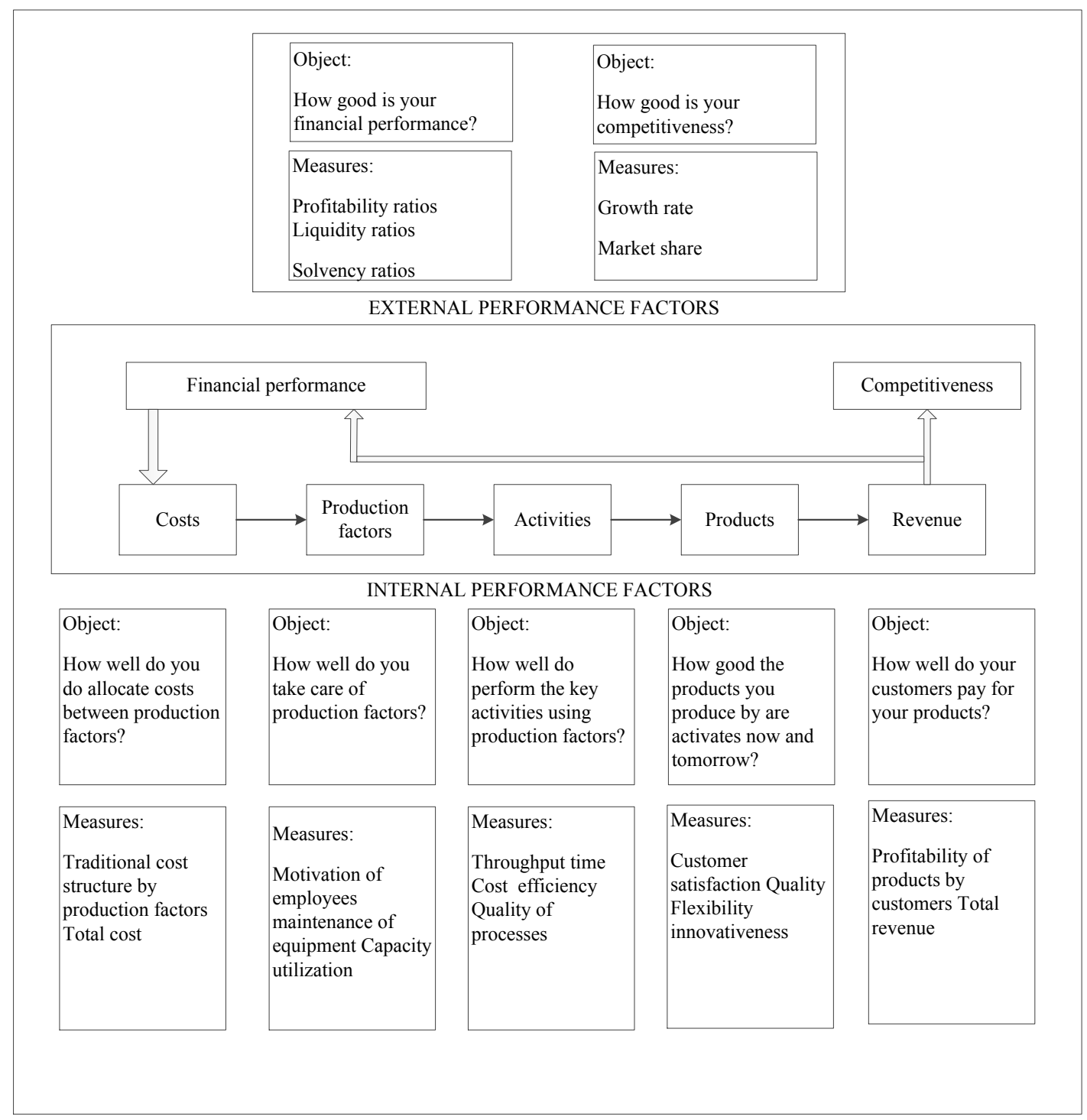

Figure 2. IPMS Model (Laitinen, 2002)

An extensive survey was conducted by Taticchi et al. (2010) to review the existing literature, covering over 6600 journal articles on performance measurement and management and performance measurement systems (PMSs) over a period of 40 years of publications. It was observed that interest in performance measurement and management subject increased in the last 20 years and it is also noted that the evolution of focus on performance from a financial perspective is geared towards focussing on performance from a non-financial perspective, see Figure 3. However, from previous studies it is understood that there was a significant lack of work in measuring and assessing SMEs performance. A similar statement was published more than ten years ago by Hudson et al. (2001), which stated that despite the extensive research that has been carried out to investigate the needs and characteristics of performance measurement systems in large organisations, there is a considerable lack of published research relating to SMEs. 


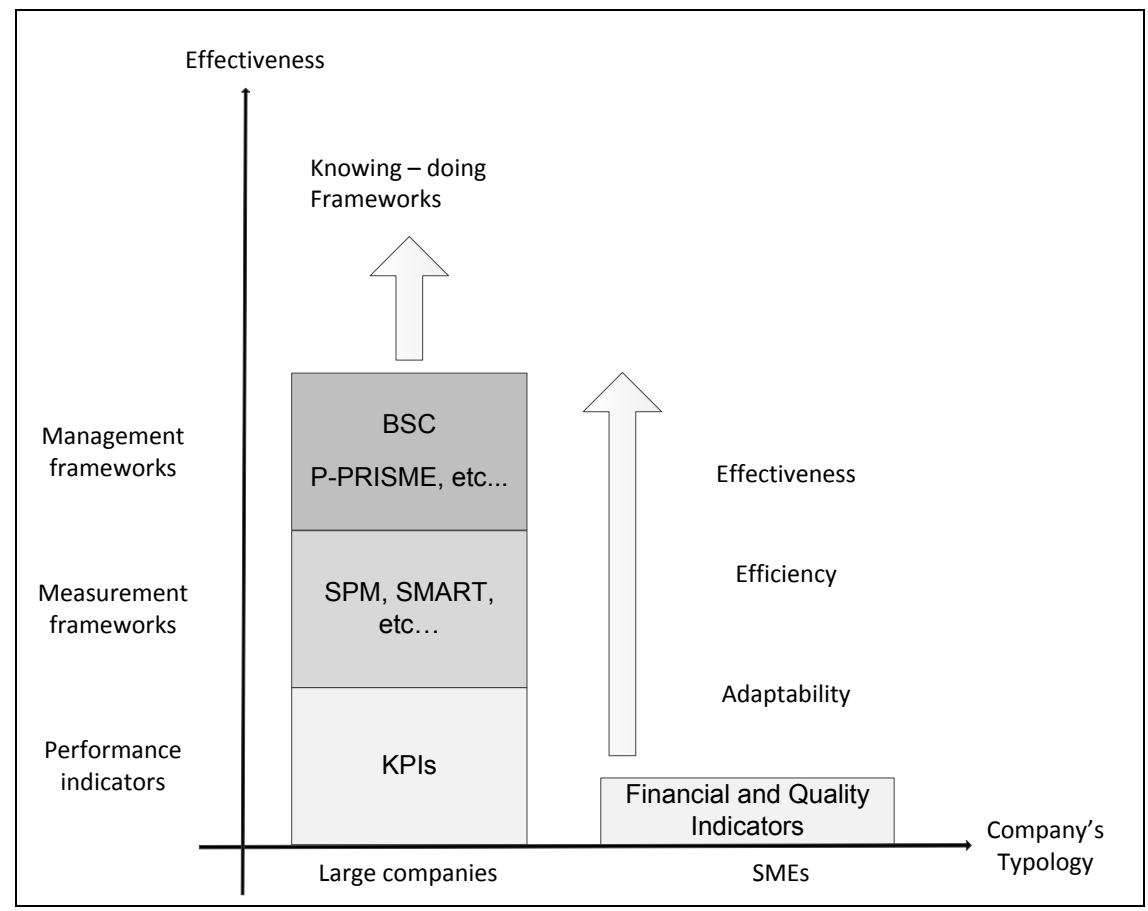

Figure 3. Large Companies and SMEs Future Areas of Research (Taticchi et al., 2010)

\section{Assessment methodologies}

According to Wiele et al. (1995), a self-assessment is defined as "a comprehensive and systematic review of an organization's activities and results referenced against a model of business excellence. It allows the organization to discern clearly its strengths and areas in which improvements can be made and culminates in planned improvement actions which can be monitored for progress". In spite of this fact, they illustrate that the process of measurement is particularly effective in SMEs and allows them to continuously improve their performance (Cassell et al., 2001; St-Pierre and Delisle, 2006) and yet searching the literature reveals that there is no adequate assessment methodology for SMEs. The next section evaluates several manufacturing assessment methodologies.

Method one. The aim of the maturity grids method is to codify best practice understanding of what might be regarded as good and bad practice along with a number of intermediaries in an accessible way to enable opportunities for improvement to be determined (Moultrie et al., 2007). The method is structured in such a way as to meet the needs of SMEs. Maturity grids were proposed by Garengo et al. (2005) and Cocca and Alberti, (2010) as appropriate assessment methods for SMEs because they are simple and user-friendly, do not require much time to implement, limited resources are needed and they do not need external consultants. 


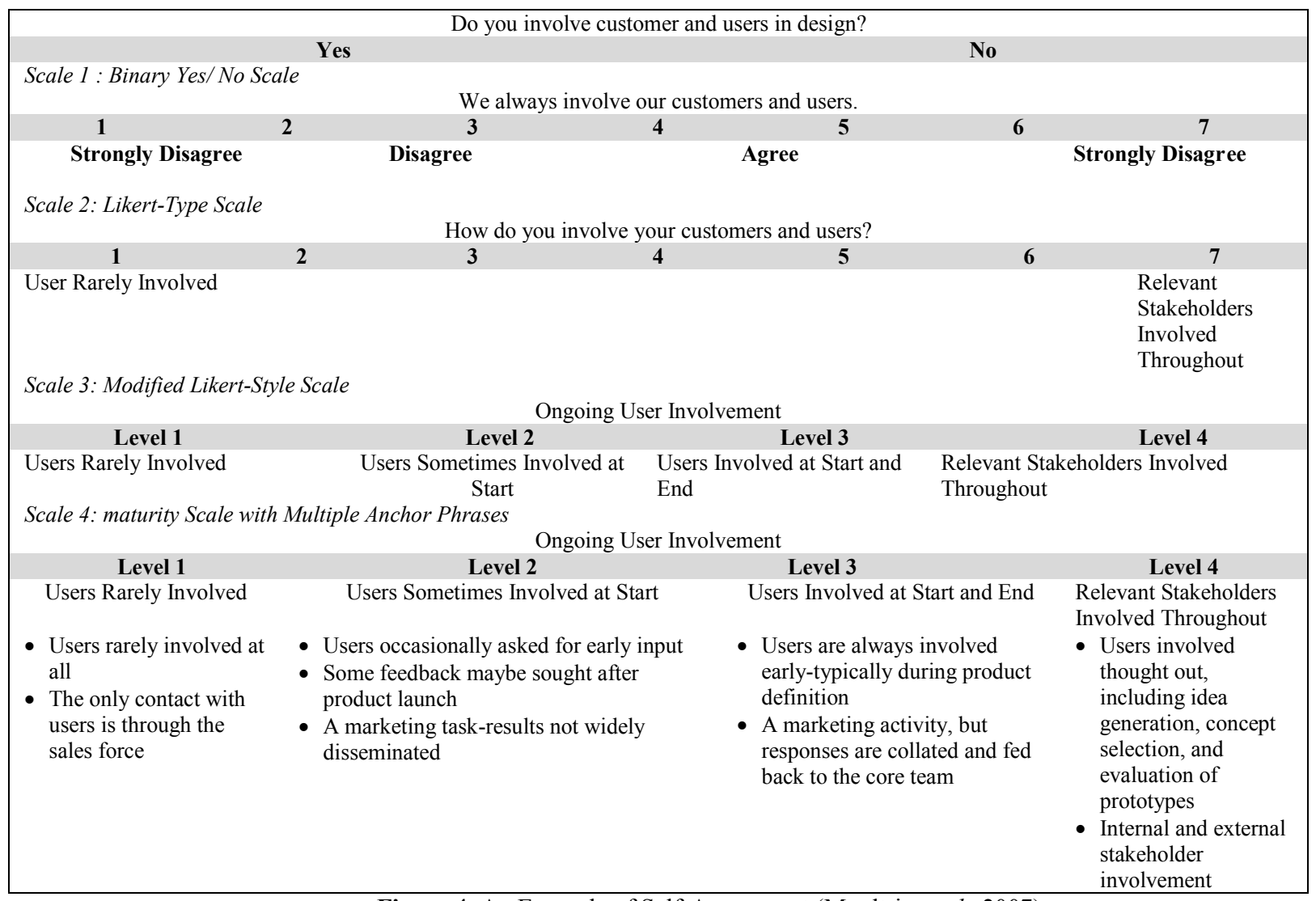

Figure 4. An Example of Self-Assessment (Moultrie et al., 2007)

Method two. A methodology introduced by (Peter W) that was adopted from the European Foundation for Quality Management (EFQM) which is based on qualitative assessment. Figure 5 illustrates this method.

\begin{tabular}{|c|c|c|c|c|}
\hline \multicolumn{5}{|l|}{ PROCESS RESULTS } \\
\hline Score & 3 & 6 & 8 & \\
\hline $\begin{array}{l}\text { Few procedures } \\
\text { exist apart from } \\
\text { financial controls. } \\
\text { Everyone does their } \\
\text { best and fire } \\
\text { fighting is the norm. } \\
\text { changes are made to } \\
\text { fix problems as and } \\
\text { when appropriate. }\end{array}$ & $\begin{array}{l}\text { Procedures have } \\
\text { been written and } \\
\text { imposed. } \\
\text { A bureaucratic } \\
\text { system exists with } \\
\text { little chance for } \\
\text { improvement. } \\
\text { Mistakes are seen as } \\
\text { 'bad' but are rarely } \\
\text { used to make } \\
\text { improvements. }\end{array}$ & $\begin{array}{l}\text { Critical processes are } \\
\text { owned and there is } \\
\text { support to monitor } \\
\text { and improve them. } \\
\text { Ownership is } \\
\text { assigned } \\
\text { to management who } \\
\text { review corrective } \\
\text { action etc. }\end{array}$ & $\begin{array}{l}\text { Meeting customer } \\
\text { needs is clearly } \\
\text { seen by all as the } \\
\text { purpose of all } \\
\text { activities. } \\
\text { Procedures and } \\
\text { operating standards } \\
\text { are owned by the } \\
\text { operators, managers } \\
\text { and suppliers. }\end{array}$ & $\begin{array}{l}\text { The system ensures that all } \\
\text { stakeholder needs are met } \\
\text { by existing and new } \\
\text { services. Customers find it } \\
\text { easy to do business with the } \\
\text { organisation. Feedback } \\
\text { leads to improvement and } \\
\text { innovation. }\end{array}$ \\
\hline
\end{tabular}

Figure 5. An Example of Self-Assessment Matrix (Ahmad and Dhafr, 2002)

Method three. An assessment tool was introduced by (Gilgeous and Gilgeous, 2001). In this method, the majority of assessing elements are qualitative, and therefore quantitative performance measurement cannot be obtained. An example of this method is shown below: 
A7.Please tick the statement which best describes your performance as a manufacturing company in relation to your competitors:

- Considerably better than competitors

- Clearly better than competitors

- Marginally better than competitors

- Sometimes marginally better than competitors

- About the same as most competitors

- Slightly lower than the average of most competitors

- Usually marginally worse than most competitors

- Usually worse than competitors

- Consistently worse than competitors

Figure 6. An Example of Self-Assessment (Gilgeous and Gilgeous, 2001)

Method four. Another method developed by Ahmad and Benson (1999) was reviewed, an example is shown in Figure 7. Implementing this method allowed assessment of the company performance in a quantitative manner, as well as availability of a set of supporting equations, which can be utilised after generating data from the practice and assessing accurate performance. These equations will help to define formula and source of data.

1. Do you routinely measure the $\%$ of On-Time-In-Full delivery (OTIF) delivery performance?

\begin{tabular}{|llll}
\hline Yes & Th & Phear measure...........
\end{tabular}

2. Do you routinely measure the customer complaints - $\%$ of orders delivered?
Yes

$$
\text { No }
$$
This year measure.
Previous year measure.

3. Do you routinely measure the $\%$ Product Rate?

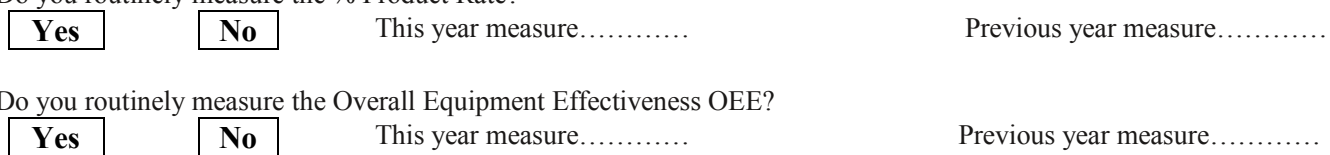

Figure 7. An Example from the KPI Assessment (Ahmad and Benson, 1999)

Several assessment methods were identified in the existing literature; these methods have some aspects which make them suitable for implementation in SMEs, particularly the maturity grids method. The identified assessment methods were assessed based on the suitability of these methods for their use in assessing manufacturing SMEs and meeting the aims of this study. The method introduced by Ahmad and Benson (1999) was determined to be an appropriate method for this study, as the rest of the methods were neither able to draw a quantitative performance measure, nor able to meet the aim of this study. Thus, an assessment model has been developed based on Ahmad and Benson's methodology, with some modifications in order to meet the purpose of this study. 


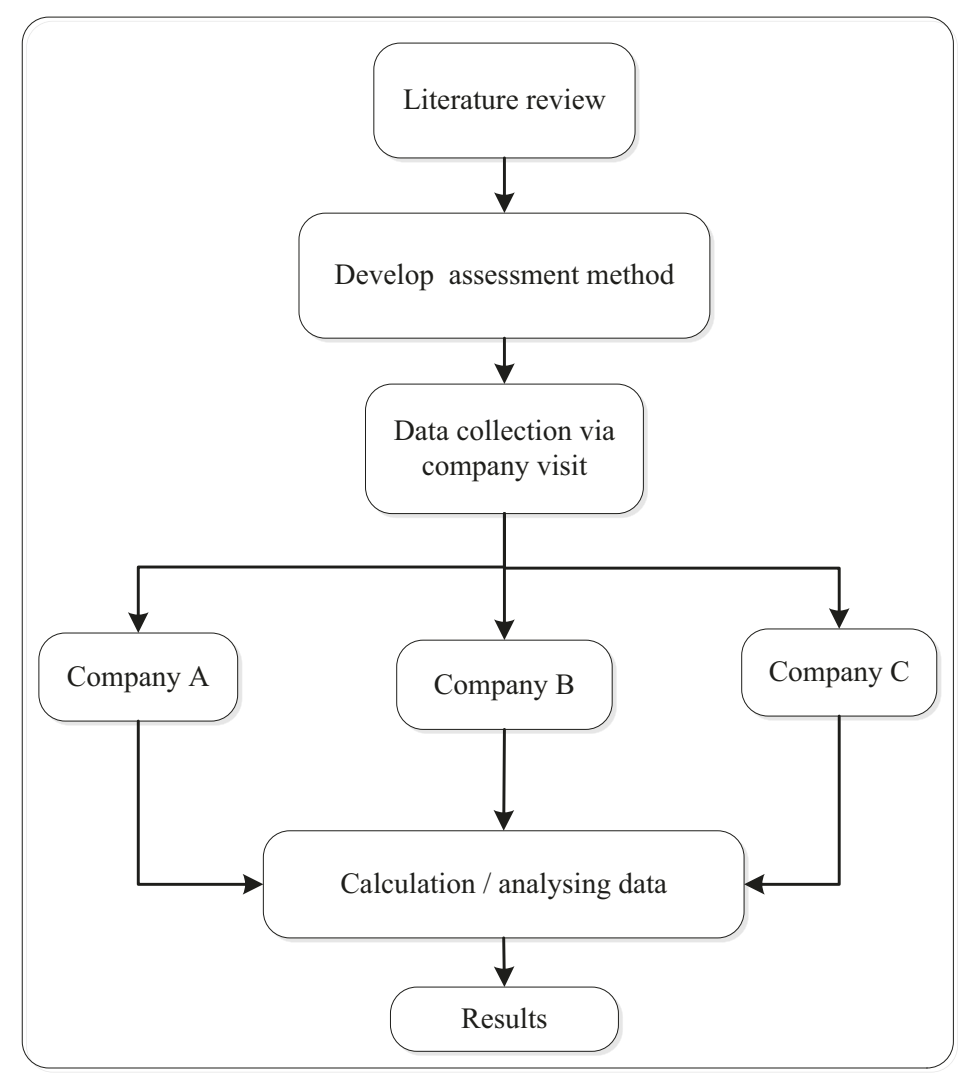

Figure 8. Methodology of the Study.

\section{Develop assessment methodology}

On the basis of the previous observations, the assessment methodology was developed. It is essential to take into account some issues in order to develop a methodology to be used in manufacturing SMEs context, such as cost effectiveness and straightforward implementation. The structure of the methodology proposed is a closedloop methodology consisting of two parallel phases, followed by a third phase as shown in Figure 9.

- Phase one: Opportunities and benefits. In this phase a company will identify the opportunities and benefits that are already available within the company. Ten questions are used to capture the degree (low, medium or high) of potential improvement in some areas from the company perspective. These questions aim to cover the key aspects of potential improvements. This can help top management decide which area of the company has more potential for improvement, and thus should be given more consideration.

- Phase two: KPIs. It consists of twelve questions used to determine the current performance level of the company, as well as determining the world class performance level. These levels are then compared. The world class performance in this methodology is considered as the best performance that has ever been achieved by the company. Conducting this step will permit the current performance gap be determined. Gap = best performance could be achieved - current performance

- Phase three: As a result of conducting phases one and two, a clear image of the company performance can be drawn in terms of the opportunities and benefits available as well as performance gaps; this will enable top management to review their approach of doing business and take achievable and appropriate decisions for improvement. However, it may be difficult for SMEs to address all the issues at the same time with limited resources, in such a case a company could set priorities depending on the company policy, capability and market situation. This will enable the company to begin addressing the most important issues first, and tackling the remaining issues over time. 
According to Taticchi et al. (2010), performance measurement has diverted from a financial perspective to a non-financial perspective; thus, the proposed methodology in this study focuses on the non-financial perspective. The advantages of this methodology cover areas such as quality, delivery and customer complaints, which are considered by many researchers as the most important aspects of manufacturing performance. In addition, this methodology has two parallel phases, which means the phases do not depend on each other. Therefore, this makes the proposed methodology more effective as each phase has a degree of freedom. Thus, if the outcome of one phase cannot be achieved, it will not have an effect on the other phase but some value can still be gained. Finally, the introduced methodology concept identifies the most urgently required actions and therefore provides a road map for SMEs to start a continuous improvement journey to becoming a world class manufacturing company.

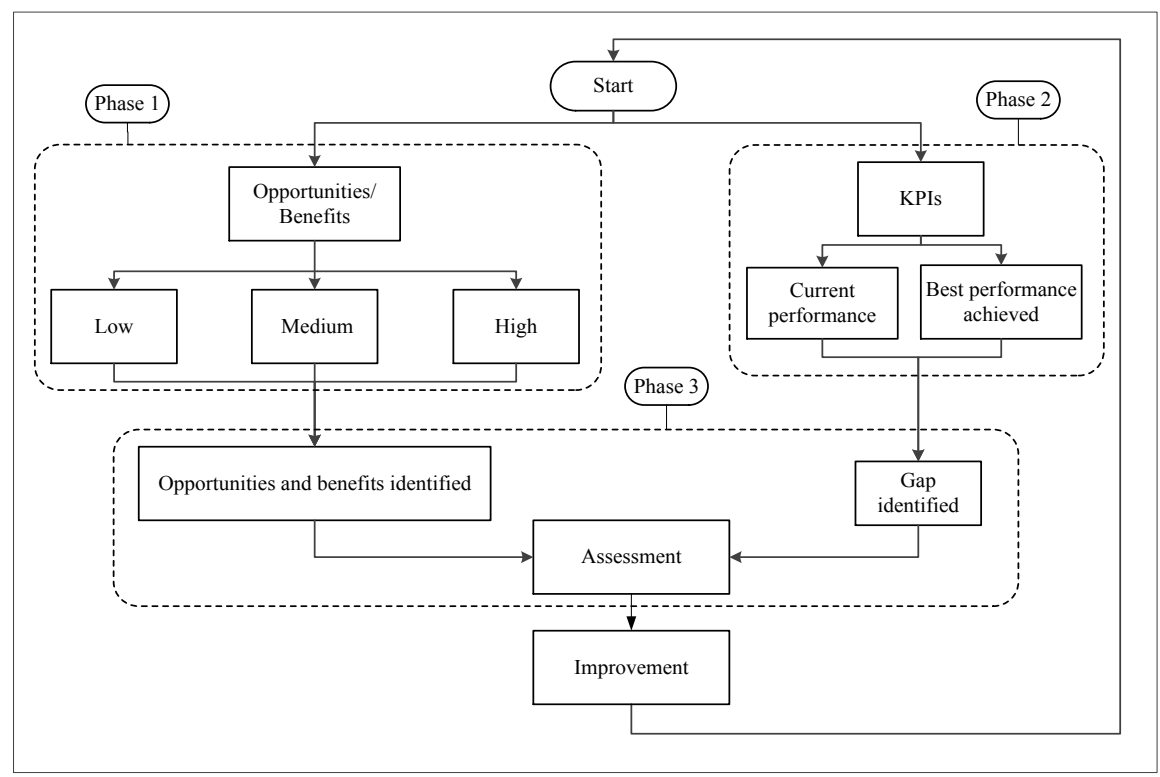

Figure 9. The Proposed Methodology 
Table I. Relationships between Proposed Methodology and Existing Methodology.

\begin{tabular}{|c|c|c|c|c|c|}
\hline Proposed methodology & $\mathbf{A}$ & B & $\mathbf{C}$ & D & $\mathbf{E}$ \\
\hline $\begin{array}{l}\text { 1.Identify opportunities and } \\
\text { benefits }\end{array}$ & 1.Vision & $\begin{array}{l}\text { 1. Name: } \\
\text { Identify business, prioritise objectives, name } \\
\text { one objective for immediate action, select a } \\
\text { project team for the next stage objectives }\end{array}$ & $\begin{array}{l}\text { 1.External factor } \\
\text { Financial } \\
\text { performance }\end{array}$ & $\begin{array}{l}\text { 1. Develop \& retain } \\
\text { commitment }\end{array}$ & $\begin{array}{l}\text { 1. At the strategic level to } \\
\text { determine external } \\
\text { measures driven by } \\
\text { stakeholder } \\
\text { perspectives }\end{array}$ \\
\hline 2.Establish the KPIs & 2.Collate and measure & $\begin{array}{l}\text { 2. Act: } \\
\text { Collect improvement suggestions from staff } \\
\text { Evaluate and select appropriate improvements } \\
\text { Develop performance measures to support } \\
\text { Improvements Identify and consult people to } \\
\text { action the improvements and the measures }\end{array}$ & $\begin{array}{l}\text { 2.External factor } \\
\text { Competitiveness }\end{array}$ & $\begin{array}{l}\text { 2.Develop \& deploy } \\
\text { communication } \\
\text { strategy for steps } 3-8\end{array}$ & $\begin{array}{l}\text { 2. Set of key performance } \\
\text { indicators at tactical } \\
\text { level }\end{array}$ \\
\hline 3.Identify current performance & $\begin{array}{l}\text { 3. Define and plan the business } \\
\text { process improvement }\end{array}$ & $\begin{array}{l}\text { 3. Use: } \\
\text { Implement selected improvements Identify } \\
\text { appropriate data collection systems Collate } \\
\text { data centrally Communicate measurement } \\
\text { information to staff Report progress towards } \\
\text { targets Action feedback from reviews }\end{array}$ & $\begin{array}{l}\text { 3. Internal factor } \\
\text { cost of } \\
\text { production } \\
\text { factors }\end{array}$ & $\begin{array}{l}\text { 3.Plan the self- } \\
\text { assessment process }\end{array}$ & $\begin{array}{l}\text { 3. At operational level, } \\
\text { measures are utilised } \\
\text { for monitoring, control } \\
\text { and improvement }\end{array}$ \\
\hline $\begin{array}{l}\text { 4.Identify the world class } \\
\text { performance }\end{array}$ & $\begin{array}{l}\text { 4. Management awareness, } \\
\text { commitment and education }\end{array}$ & $\begin{array}{l}\text { 4. Learn: } \\
\text { Review progress toward target, assess success } \\
\text { of improvements, review continued } \\
\text { appropriateness of performance measures, } \\
\text { feedback actions from review to relevant staff }\end{array}$ & $\begin{array}{l}\text { 4.Internal factor } \\
\text { Production } \\
\text { factors }\end{array}$ & $\begin{array}{l}\text { 4. Select and train people } \\
\text { directly involved in } \\
\text { the process }\end{array}$ & \\
\hline 5.Determine the gaps & $\begin{array}{l}\text { 5.Education in kaizen, shop- } \\
\text { floor awareness and } \\
\text { commitment }\end{array}$ & & $\begin{array}{l}\text { 5.Internal factor } \\
\text { activities }\end{array}$ & $\begin{array}{l}\text { 5.Conduct self- } \\
\text { assessment }\end{array}$ & \\
\hline 6. Assess the current state & 6.Check the process & & $\begin{array}{l}\text { 6.Internal factor } \\
\text { products }\end{array}$ & $\begin{array}{l}\text { 6.Establish \& } \\
\text { Implement action } \\
\text { plans }\end{array}$ & \\
\hline 7.Planning Improvement & & & $\begin{array}{l}\text { 7.Internal factor } \\
\text { revenue }\end{array}$ & $\begin{array}{l}\text { 7. Monitor progress \& } \\
\text { review self- } \\
\text { assessment process }\end{array}$ & \\
\hline
\end{tabular}

A. Khan, Z., Bali, K., and Wickramasinghe, N. (2007). "Developing a BPI framework and PAM for SMEs". Industrial Management and Data Systems, Vol. 107 No. 3, pp. $345-360$

B. Hudson, M, Lean, J, Smart, P, (2001)“Improving control through effective performance measurement in SMEs." Production Planning and Control, Vol. 12 No.8, pp. 804 - 813.

C. Laitinen, K. (2002), “A dynamic performance measurement system: evidence from small Finnish technology companies". Scandinavian journal of management, Vol. 18 No.1, pp. 65-99.

D. EFQM, Self-assessment toolbook (2003)

E. Chennell, A., Dransfield, S., Field, J., Fisher, N., Saunders, I., and Shaw, D., (2000), OPM: “A system for organizational performance measurement”. In Conference Proceedings Performance Measurement-Past, Present and Future, Cranfield University, pp. 96-103. 


\section{Case studies}

In order to capture the data requirement to answer the questions in phases 1 and 2 of the proposed methodology, a case study approach was adopted for the data collection. Visits were made to the selected companies and semi-structured interviews were conducted. The questions in the interviews have been kept as simple as possible to be answered. The case study was undertaken to assess the relevance of proposed methodology in SME context. The current investigation involved three samples from manufacturing SMEs, each located in the North-East of England. The rationale for the selection of these samples was the definition of SMEs by the European Commission (2010), whose criteria for the companies involved in this study was: "SME companies with less than 250 employees and maximum turnover of 50 million Euros or with a balance sheet total of 43 million Euros". The assessment form which was utilised in the interviews is structured as follows:

- The first part investigates the general information of the company profile with questions related to the company size, number of employees and current annual sales revenue, types of product made and year of establishment.

- The second part explores the opportunities and benefits in companies. Ten questions were designed, each question representing areas where opportunities and benefits may lie, the respondents were asked to answer the ten questions and rank potential opportunities and benefits into three levels:- low, medium, and high which should be judged against their best knowledge.

- The last part of the assessment form is the most important and the most difficult. The exact numerical values need to be determined because it needs to be calculated using some equations. Substantial effort has been made to complete this part; however, sometimes numerical values were not available. In such cases, the respondents were asked to use their best judgement to estimate the numerical value.

Furthermore, to gain a better understanding of different issues in relation to assessment practices in the company and revised or amended data obtained in assessment form, a number of collection techniques were undertaken, including participant observation, meetings with some of the company staff and review related documents. By conducting all these techniques, qualitative data about the present performance measurement systems was captured. After collecting the data, a set of equations adopted from Ahmad and Benson, (1999) were utilised, aiming to generate a list of actual performance value which will be benchmarked against the world class performance of the company. The definition of the world class performance here is the best performance they have ever achieved at any time. The theory is that the company should always be able to perform at the best performance ever achieved at any time, the argument being that if a certain level of performance could be achieved on one occasion, it should be achieved at all times. Below is set of equations which have been utilised in this study, which are also used as KPIs for the companies' performance.

- Manufacturing added value per manufacturing employee

$$
=\frac{\text { Annual turnover }- \text { variable costs }- \text { fixed costs and overheads }}{\text { number of employees }}
$$

- On time in full (OTIF) Delivery performance

$$
=\frac{\text { Number of defect free on time shipments }}{\text { Total number of all shipments }}
$$

- Adherence to production plan

$$
=1-\frac{\text { actual production }- \text { forecast production }}{\text { forecast production }} * 100
$$


- Customer complaints

$$
=\frac{\text { number of complaints }}{\text { total number of despatches }} * 100
$$

- Product rate

$$
=\frac{\text { good production }+ \text { potential production in periods of no demand }+ \text { failed quality control }}{(8760 * M P R)-\text { production lost due to shutdown) }}
$$

Where:

MPR = Maximum output that has been achieved for any continuous seven day period.

$8760=$ Total number of hours operation per year

- Quality rate

$$
=\frac{\text { good production }}{\text { good production }+ \text { failed quality control }}
$$

- Availability is $100 \%$ less the sum of scheduled and unscheduled downtime

$$
\begin{aligned}
& =\frac{8760-(\text { number of hours of total shutdown })}{8760} \\
& \text { OR } \\
& =100-(\text { scheduled downtime }+ \text { unscheduled downtime })
\end{aligned}
$$

- $\quad$ Process Capability $(\mathrm{CpK})$

$$
=\frac{\text { lower of (upper spec }- \text { average })}{3 \text { sigma }}
$$

- $\quad$ Stock turn

$$
=\frac{\text { annual sales }}{\text { total stock value }}
$$

\section{Results}

The previous studies emphasised the need and the importance of developing an appropriate methodology to measure and assess manufacturing SMEs performance. Many studies have stated that SMEs have not attained a mature level of assessment methodology. More recent literature highlights the need for further investigation in these areas and shows the benefits that can be gained from implementing an assessment methodology are not limited to large companies, but SMEs can also benefit from such techniques. Moreover, all participants in this study acknowledged that there is no proper approach to assess their company's performance and this is consistent with the results obtained from the literature.

In this study, the developed methodology focuses on the opportunities and benefits, and determines the KPIs utilised to identify the performance gaps. The data obtained by applying the developed assessment methodology to the three SMEs shows the following results. 
In Table II the opportunities and benefits of companies A, B and C, can be seen. It demonstrated that for all three companies, the company output is considered to be a high potential, whereas the following three points are considered to be low potential areas for gaining opportunities and benefits:

- Increasing employee training and empowerment.

- Improving material and source goods delivery, reliability and reduced stock levels.

- Potential of customer feedback adding value to the product.

The companies differ in some areas, for example the potential for reducing the total maintenance costs in company $\mathrm{A}$ is high, company $\mathrm{B}$ is medium and in company $\mathrm{C}$ is low.

Table II. Results Obtained from Opportunities/Benefits Phase.

\begin{tabular}{|c|c|c|c|c|}
\hline NO & Opportunities/Benefits & Company A & Company B & Company C \\
\hline 1 & Potential of increasing company output & $\mathrm{H}$ & $\mathrm{H}$ & $\mathrm{H}$ \\
\hline 2 & Potential of improving capacity & $\mathrm{H}$ & $\mathrm{M}$ & $\mathrm{M}$ \\
\hline 3 & Potential of product consistency improvement & M & $\mathrm{L}$ & $\mathrm{L}$ \\
\hline 4 & Potential of improving uptime & $\mathrm{H}$ & M & $\mathrm{L}$ \\
\hline 5 & $\begin{array}{l}\text { Potential of reducing average time to reach product } \\
\text { specification }\end{array}$ & $\mathrm{H}$ & $\mathrm{L}$ & $\mathrm{L}$ \\
\hline 6 & $\begin{array}{l}\text { Potential of improving product delivery performance } \\
\text { and reduced cost of final product stocks }\end{array}$ & $\mathrm{L}$ & $\mathrm{M}$ & $\mathrm{L}$ \\
\hline 7 & $\begin{array}{l}\text { Potential of improving material and source goods } \\
\text { delivery, reliability and reduced quality stocks }\end{array}$ & $\mathrm{L}$ & $\mathrm{L}$ & $\mathrm{L}$ \\
\hline 8 & $\begin{array}{l}\text { Potential of customer feedback adding value to the } \\
\text { product }\end{array}$ & $\mathrm{L}$ & $\mathrm{L}$ & $\mathrm{L}$ \\
\hline 9 & Potential of reducing total cost of maintenance & $\mathrm{H}$ & $\mathrm{M}$ & $\mathrm{L}$ \\
\hline 10 & $\begin{array}{l}\text { Potential of increasing employee training and } \\
\text { empowerment }\end{array}$ & $\mathrm{L}$ & $\mathrm{L}$ & $\mathrm{L}$ \\
\hline
\end{tabular}

Although opportunities and benefits can be determined from Table II, and the company can identify the greatest potential for improvements, which in itself is not sufficient to draw a clear picture and assess the company's performance. Therefore, the second phase of the methodology is providing the assessment of the current performance of the company. The essential element of this phase is the calculation of KPIs, the subsequent outcomes and the ranking of the results using a scale from 0 to 10 , where 0 represents low performance and 10 represents world class performance, thus facilitating the identification of performance gaps and determining the overall company performance.

From Table III and Figure 10, it can be noted that the KPIs can be divided into three categories based on their proximity to world class performance; some of the KPIs in the three companies are close to world class performance scoring 9,8 and 7 in the rank scale, they are:

- Manufacturing added value per employee

- OTIF

- Customer complaints

Other KPIs which are considered to be far from achieving world class performance scoring 1 in the rank scale are:

- Maintenance cost

- Process capability

- Change time of routine tasks affecting reduction 
However, there are some KPIs in between the extremes which are:

- Adherence to production plan

- $\quad$ Product rate

Also, it was observed that there is clear variance in KPI 9 (availability) as this KPI scored 1 in the ranking scale for company A, 6 for company B and 9 for company $\mathrm{C}$. 
Table III. Summary of KPIs Results.

\begin{tabular}{|c|c|c|c|c|c|c|c|c|c|c|}
\hline \multirow[t]{2}{*}{ No } & \multirow[t]{2}{*}{ KPIs } & \multicolumn{3}{|c|}{$\begin{array}{c}\text { Actual } \\
\text { performance }\end{array}$} & \multicolumn{3}{|c|}{ World Class } & \multicolumn{3}{|c|}{$\begin{array}{c}\text { Gap } \\
\text { performance }\end{array}$} \\
\hline & & $\mathbf{C A}$ & $\mathbf{C B}$ & $\mathbf{C C}$ & CA & $\mathbf{C B}$ & $\mathbf{C C}$ & CA & $\mathbf{C B}$ & $\mathbf{C C}$ \\
\hline KPI 1 & Manufacturing added value per employee & 9 & 6 & 9 & 10 & 10 & 10 & 1 & 4 & 1 \\
\hline KPI 2 & OTIF & 9 & 7 & 9 & 10 & 10 & 10 & 1 & 3 & 1 \\
\hline KPI 3 & Absenteeism & 9 & 3 & 8 & 10 & 10 & 10 & 1 & 7 & 2 \\
\hline KPI 4 & Customer complaints & 8 & 8 & 9 & 10 & 10 & 10 & 2 & 2 & 1 \\
\hline KPI 5 & Adherence to production plan & 6 & 6 & 7 & 10 & 10 & 10 & 4 & 4 & 3 \\
\hline KPI 6 & Quality rate & 6 & 9 & 9 & 10 & 10 & 10 & 4 & 1 & 1 \\
\hline KPI 7 & Product rate & 4 & 3 & 7 & 10 & 10 & 10 & 6 & 7 & 3 \\
\hline KPI 8 & Stock turn & 2 & 4 & 1 & 10 & 10 & 10 & 8 & 6 & 9 \\
\hline KPI 9 & Availability & 1 & 6 & 9 & 10 & 10 & 10 & 9 & 4 & 1 \\
\hline KPI 10 & Maintenance cost & 1 & 1 & 1 & 10 & 10 & 10 & 9 & 9 & 9 \\
\hline KPI 11 & Process capability (CpK) & 1 & 1 & 1 & 10 & 10 & 10 & 9 & 9 & 9 \\
\hline KPI 12 & Change time of routine tasks affecting reduction & 1 & 1 & 1 & 10 & 10 & 10 & 9 & 9 & 9 \\
\hline Total Score & & $47.5 \%$ & $45.8 \%$ & $59.1 \%$ & & & & $52.5 \%$ & $54.1 \%$ & $40.8 \%$ \\
\hline
\end{tabular}

$C A=$ company $A, C B=$ company $B, C C=$ company $C$. 


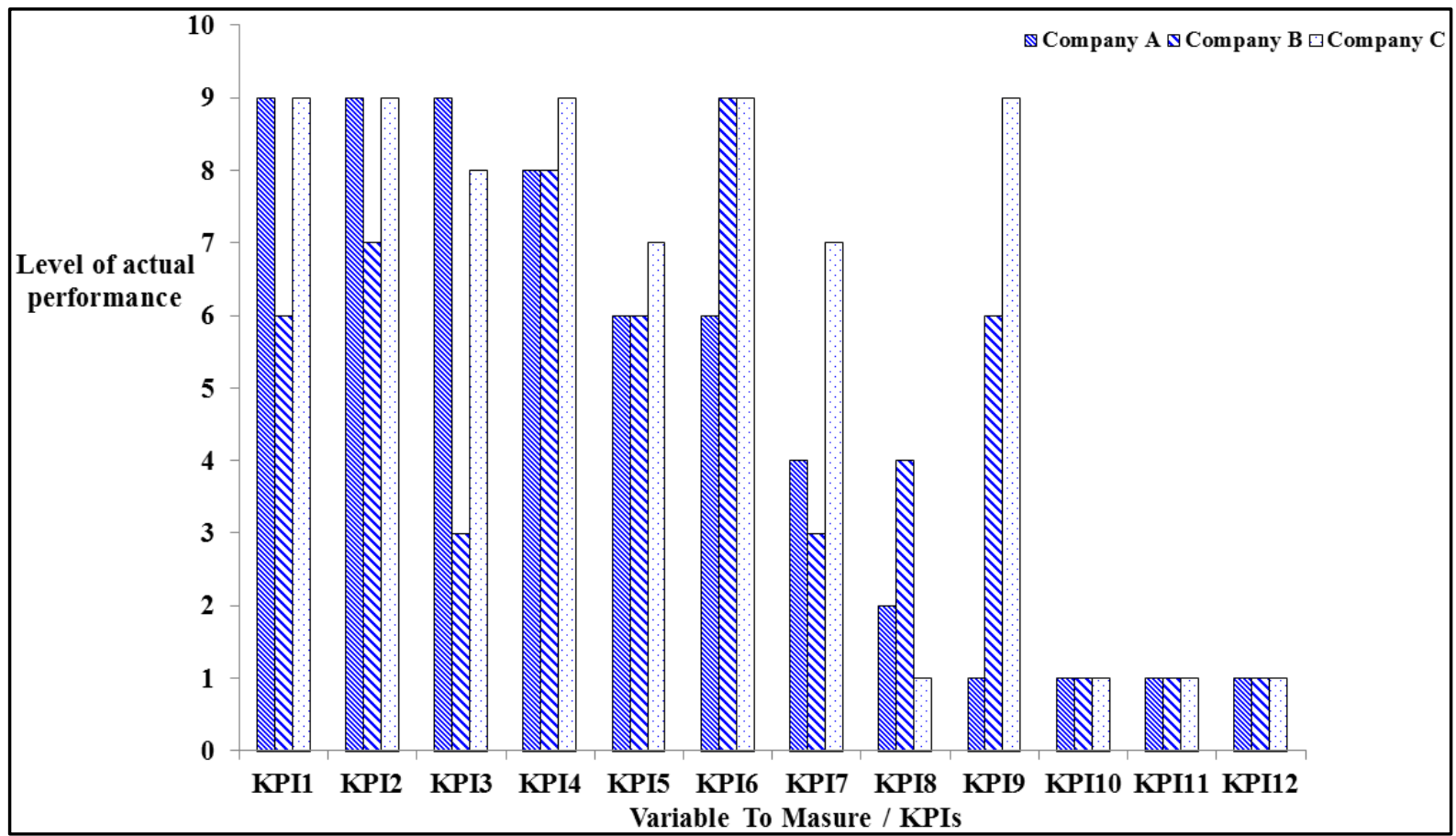

Figure 10. Performance Gaps in Companies.

Interpretation of the data was carried out individually, as shown in Figures 11 and 12. Data from company A illustrates the performance gaps and uses $\mathrm{ABC}$ classifications to categorise the KPIs according to their gap performance; the higher performance volume, which in this case was close to a world class performance, was coded as A category; low performance volume was coded as D category and the average performance of KPIs was considered to be within $\mathrm{B}$ and $\mathrm{C}$ categories. This technique will ensure that the lowest performing KPIs will be given greater scrutiny and consideration in order to address the problem. 


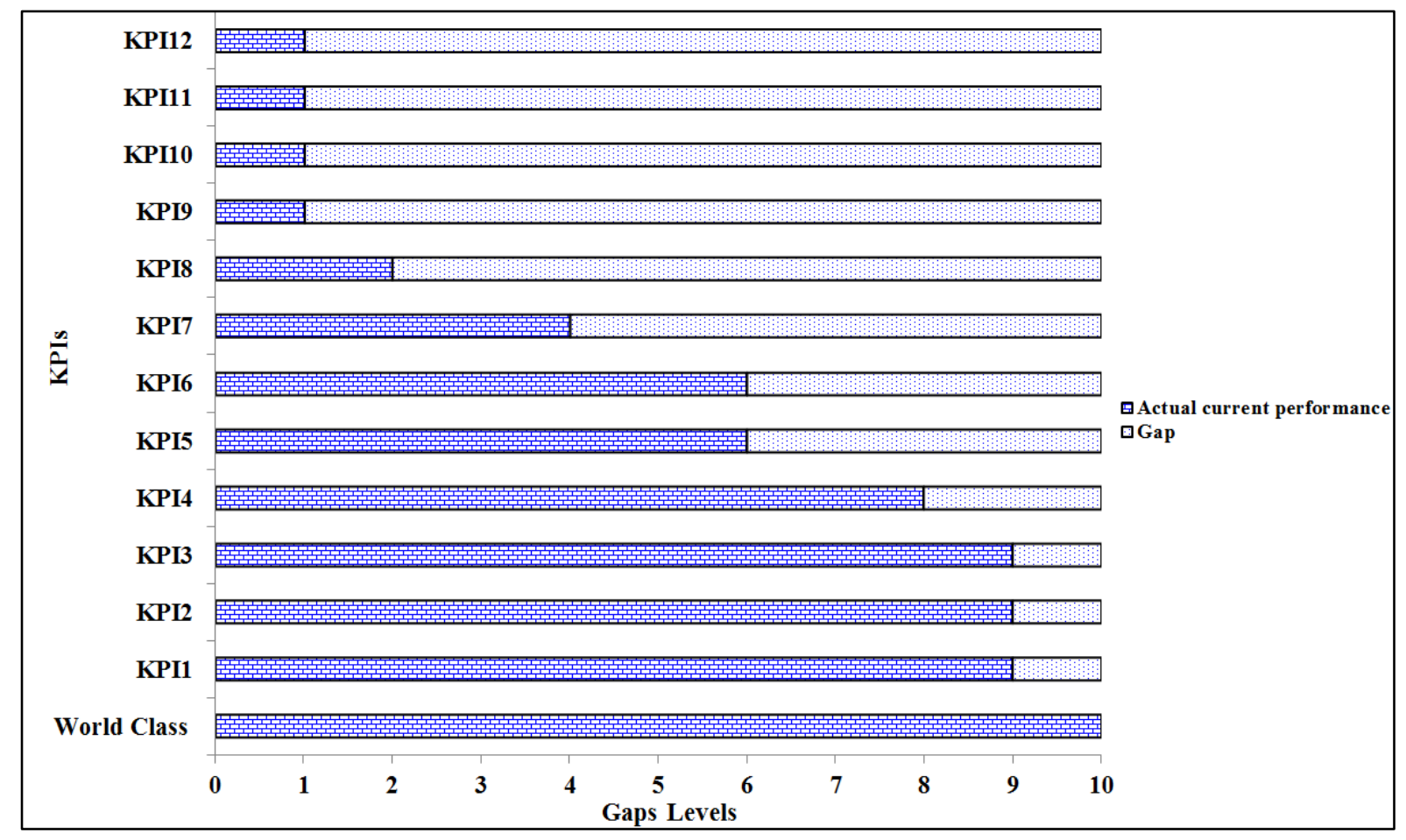

Figure 11. Performance Gaps in Company A

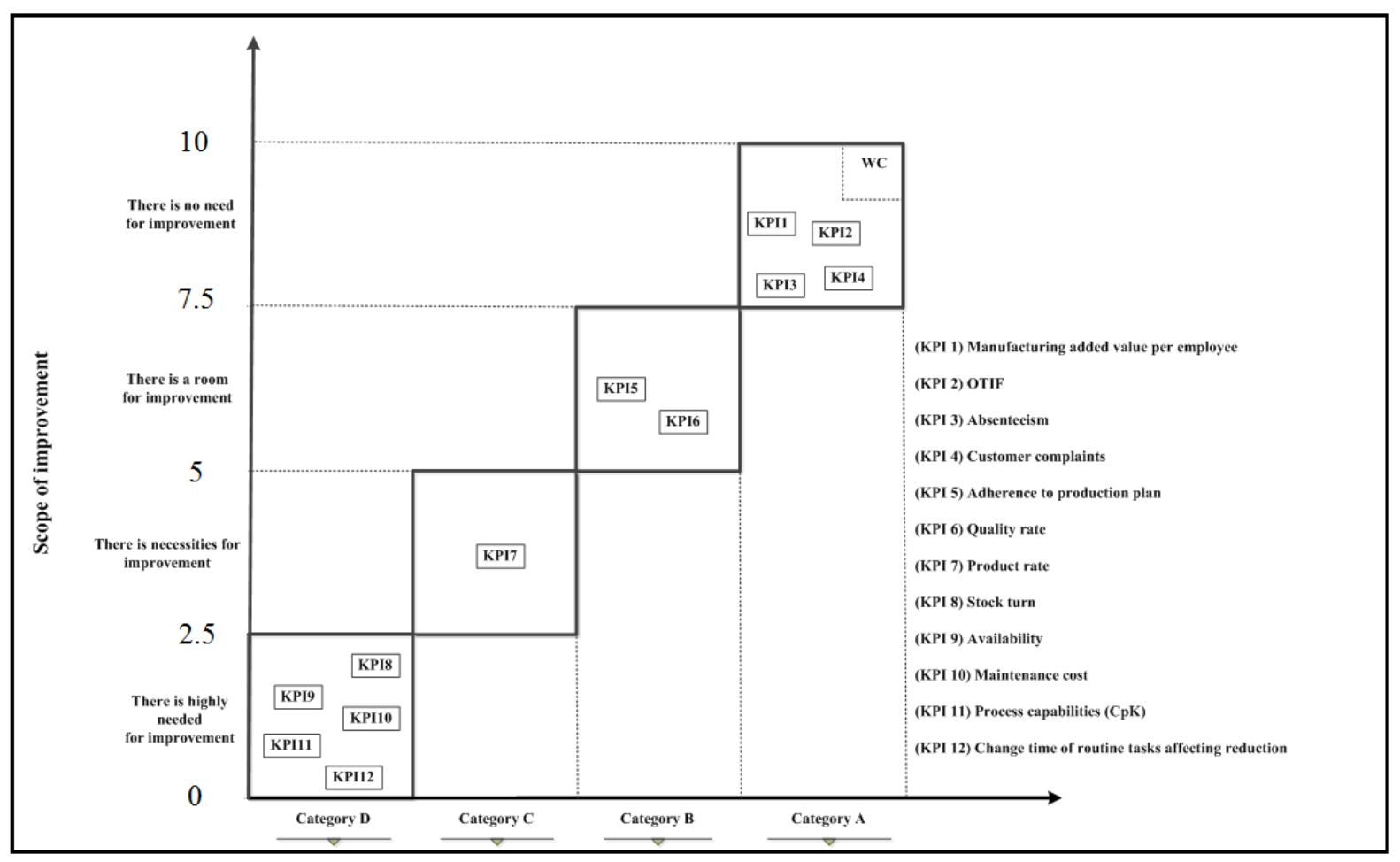

Figure 12. Categorisation of KPIs for Company A

The total score of the actual company's performance can be identified, as shown in Table III, by adding the entire total score determined by their areas of performance and ranking. Company A scored 47.5\%; hence, based on the scale shown in Table IV, the current performance of the company was placed in the average zone. 
Table IV. Percentage Shows Company Status.

\begin{tabular}{|c|c|c|}
\hline Percentage & Status & Description \\
\hline $0-20$ & $\begin{array}{l}\text { POOR } \\
\end{array}$ & $\begin{array}{l}\text { The company manufacturing has considerable scope } \\
\text { for improvement. The company requires a detailed } \\
\text { operational excellence assessment, with a high } \\
\text { likelihood of significant benefits through } \\
\text { manufacturing, maintenance, and operational changes. }\end{array}$ \\
\hline $21-40$ & BELOW AVERAGE & $\begin{array}{l}\text { The company manufacturing performance has scope } \\
\text { for improvement. A detailed analysis of the operational } \\
\text { and maintenance excellence is required to assess the } \\
\text { potential improvements. }\end{array}$ \\
\hline $41-60$ & AVERAGE & $\begin{array}{l}\text { The company appears to have manufacturing and } \\
\text { maintenance practices which, while average, could be } \\
\text { improved. The assessment has highlighted some areas } \\
\text { of the company with further potential. }\end{array}$ \\
\hline $61-80$ & GOOD & $\begin{array}{l}\text { The company has good manufacturing and } \\
\text { maintenance practices and it appears to be exploiting } \\
\text { learning opportunities. }\end{array}$ \\
\hline $81-100$ & WINNING & $\begin{array}{l}\text { The site is aware of the scope for further maintenance } \\
\text { and manufacturing improvement. The company is } \\
\text { approaching a winning standard and demonstrating } \\
\text { leading manufacturing and maintenance practices. }\end{array}$ \\
\hline
\end{tabular}

(Ahmad and Benson, 1999)

\section{Discussion}

It has been stated in the literature review that SMEs represent the most important driver of the economy; therefore, it is necessary to improve their competitiveness. Since assessing company performance is a vital process for company improvement, an attempt to develop an assessment methodology which can be adopted by SMEs was conducted in this study. Prior work has documented the effectiveness of the assessment methodology in improving company performance, yet the attention being paid to SMEs is not adequate. Most of these studies have focused on large companies and are based on qualitative assessment. In this study, the literature was reviewed in order to identify the existing assessment methodology and the assessment methodology was developed and evaluated through three SME case studies. There are many assessment methodologies used by companies to assess their performance; some are based on questionnaires and the rating of aspects, whereas others use semi-structured interviews. However, most of these methodologies were developed to refer to a particular company requirement or industrial aspects. Therefore, the measures are derived from the needs of a certain company and cannot be applied for most other companies. In general, although the assessment methodologies are not widely used in manufacturing SMEs, they are highly appreciated in the literature, as it is believed that assessment methodologies are very useful for improving company performance.

Phase one in this methodology enabled classification of the potential opportunities and benefits into three levels: high, medium and low, as shown in Table II. Conducting this step is valuable because it is not possible to give equal importance to all areas, particularly to SMEs with limited resources. This will assist the companies in focusing on the areas which have high potential to gain benefits. In this phase, all the participants in this study believe that the potential for increasing the company output is high. This is not surprising because there is always room for increasing the output; it is a good indicator that the companies believe they could do more, as it shows that they are to some extent ready to improve. However, an issue companies should take into consideration is that the increase in output should be to fulfil customer demands; otherwise the company will end up having excessive finished goods on their hands with no demand for them. This will increase the 
inventory level and cause many problems, therefore companies should know when and how they need to increase their output. Also, the results show that there are other areas to be considered by the three companies which have low potential for benefits, thus these areas could be given less priority as expected benefits are low, at least in the present scenario. Moreover, due to differences in style and priorities, each company reflects the potential of opportunities and benefits differently in various areas. This occurred in the areas of improving uptime and reducing total cost of maintenance. In both areas, the opportunities and benefits in company $\mathrm{A}$ is high, in company $\mathrm{B}$ is medium and in company $\mathrm{C}$ is low.

Phase two in this methodology determines the gaps in the company performance through calculation of the KPIs. From Table III it can be noted that there is variance in the KPIs, such as in KPI 9. This shows that this methodology is effective in highlighting the gaps in the current companies' performance. Additionally, there are some KPIs which are close to world class performance; these may be considered as important parameters for the companies which highlights that it is not necessary to take action against these KPIs in the present scenario. However, this is not consistent with some other KPIs which have a low performance score on the scale; this may be because these KPIs have been deemed less important by top management, or have less impact on the company's performance. Also, Table III shows the overall company performance can be identified by the sum of the ranks which are represented here as a weight of the KPIs and converted to a percentage. For example, the overall performance of company A is $47.5 \%$. Therefore, according to this performance, the company is placed in the average zone. According to Table IV, company A has scope for improvement; the company appears to have average manufacturing and maintenance practices which could be improved. The assessment has highlighted areas of the company with further potential.

The investigation has also revealed that according to the categories clarified in Figure 12, a company can set these KPIs according to their priorities, in order to determine which KPIs need immediate action and can be addressed later; this will support the company to make decisions that are realistic and achievable. However, this needs to be arranged in accordance with the company's requirements and capability as prioritising the KPIs differs from one company to another depending on the company's strategy. The introduced assessment methodology differs mainly from the previous methodology in its reference to identify the available opportunities and benefits within the company in order to make use of them, and also to quantify the gaps to allow the company to set theoretical performance targets as a source of performance benchmarks. This methodology is considered as a first step towards improvement for SMEs because it will enable the SMEs to develop guidelines in order to adopt effective and more appropriate improvement tools.

\section{Conclusion}

The main purpose of this study is to develop the assessment methodology for manufacturing SMEs in order to quantify current performance and determine the opportunities and benefits throughout the company. The literature has indicated that there is a need for more research into performance measurement and benchmarking practice which can be adopted by SMEs. Evidence suggests that no universal assessment method exists which is appropriate for all companies. Various assessment methods have been proposed, with little attention paid to developing measurement and assessment methods suitable for adoption by manufacturing SMEs. Evidence in this study shows that assessing and measuring the manufacturing performance of SMEs is not a difficult task facing the SMEs; the real challenge for SMEs is to change their own developed culture, which believes that the assessment of performance is a difficult, costly procedure, thus the implementation of change in culture can be financially burdensome, particularly when there is doubt as to whether there will be benefits from such implementation. In fact there is an assumption that SMEs are different from large companies, thus, they require an assessment performance method specifically tailored to their unique characteristics and needs. This paper describes the development of an assessment method which can be used by manufacturing SMEs to assess their performance. Based on the outcomes of this study, the three SMEs involved have a strong belief that many opportunities and benefits can be achieved in a number of areas, resulting in motivating the SMEs to improve. The results also suggested that the implementation of the proposal method will help manufacturing SMEs to identify areas where opportunities and benefits can be gained. Likewise, from these three case studies, it can be 
concluded that the developed assessment method is an appropriate and suitable method for SMEs to assess their performance. The method can be used to identify gaps and benchmark company performance to ensure continuous improvement. This assessment will create a vision and clarify what improvement the company should make, by determining the current performance of the company and identification of areas where more opportunity and benefits are available, thus indicating where improvements can be made and which action needs to be taken. It should also be noted that the application of the method in this study is not limited to the three SMEs involved in the study; rather it is a method of assessing performance within many manufacturing SMEs in the real world. However, there are limitations to this study which could provide a basis for further research; extending the sample from three to a larger sample would be desirable in order to enhance the generalisation of the findings. Further research questions remain, namely what should be done after an assessment of the company's performance? The authors' opinion is to implement an appropriate improvement method, such as Lean tools, TQM and ERP systems, which will be decided by the respective SME management using their experience and knowledge of their own organisation and its place in the market.

\section{References.}

Ahmad, M. and Dhafr, N. (2002), "Establishing and improving manufacturing performance measures", Robotics and Computer-Integrated Manufacturing Journal, Vol. 18 No 3-4, pp. 171-6.

Ahmad, M. and Benson, R. (1999), Benchmarking in the Process Industries, ISBN: 0852954115. IChemE, Rugby.

Barrows, E. and Neely, A. (2011), Managing Performance in Turbulent Times: Analytics and Insight. New Jersey,John Wiley and Sons Inc.

Bititci U.S. (1997). "Integrated Performance Measurement Systems: A Reference Model", Proceeding of IFIP WG 5.7 Conference on Organising The Extended Enterprise, Ascona, Switzerland.

Cassell, C., Nadin, S. and Gray, M.O. (2001), "The use and effectiveness of benchmarking in SMEs", Benchmarking: An International Journal, Vol. 8 No. 3, pp. 212-22.

Chennell, A., Dransfield, S., Field, J., Fisher, N., Saunders, I., and Shaw, D., (2000), OPM: "A system for organizational performance measurement". In Conference Proceedings Performance Measurement-Past, Present and Future, Cranfield University, pp. 96-103.

Cocca, P. and Alberti, M. (2010), "A framework to assess performance measurement systems in SMEs", International Journal of Productivity and Performance Management, Vol. 59 Iss: 2 pp. 186 - 200.

Eccles, R.G. (1991), "The performance measurement manifesto", Harvard Business Review, January-February, pp. 131-7.

European commission (2010), European SMEs Under Pressure-an annual report on E U Small and Medium-sized Enterprises 2009, Directorate-General for Enterprise and Industry, European Commission, Brussels.

European Foundation for Quality Management, KalDer. (2003), Excellence one toolbook for self-assessment: creating and sustaining continuous improvement, ISBN $9052364826,9789052364827$.

Fitzgerald, L., Johnston, R., Brignall,J., Silvestro, R. and Voss, C. (1991), "Performance Measurement in Service Businesses", The Chartered Institute of Management Accountants, London.

Garengo, P., Biazzo, S. and Bititci, S. (2005), "Performance measurement systems in SMEs: a review for a research agenda", International Journal of Management Reviews, Vol. 7 No. 1, pp. 25-47.

Gilgeous,V. Gilgeous, M. (2001), "A survey to assess the use of a framework for manufacturing excellence", Integrated Manufacturing Systems, Vol. 12 Iss: 1 pp. 48- 58.

Hudson, M, Lean, J, Smart, P, (2001) “Improving control through effective performance measurement in SMEs", Production Planning and Control, Vol. 12 No.8, pp. 804 - 813.

Hudson, M., Smart, A., and Bourne, M. (2001) "Theory and practice in SME performance measurement systems", International Journal of Operations \& Production Management, Vol. 21 Iss: 8, pp.1096-1115.

Kaplan, R., and Norton, D.(1992), "The balanced scorecard: measures that drive performance", Harvard Business Review, Jan-Feb, $71-79$.

Kaplan, S. and Norton, D. (1996), “The Balanced Scorecard: Translating Strategy into Action”, Harvard Business School Press, Boston, MA.

Keegan, P, Eiler, G. and Jones, R. (1989). Are your performance measures obsolete? Management Accounting, 70, 45-50.

Kennerley, M. and Neely, A. (2003) "Measuring performance in a changing business environment", International Journal of Operations \& Production Management, Vol. 23 Iss: 2, pp.213 - 229.

Kennerley, M. and Neely, A. (2002), "A framework of the factors affecting the evolution of performance measurement systems", International Journal of Operations \& Production Management, Vol. 22 No. 11, pp. 1222-45.

Khan, Z., Bali, K., and Wickramasinghe, N. (2007). "Developing a BPI framework and PAM for SMEs". Industrial Management and Data Systems, Vol. 107 No. 3, pp. 345-360. 
Laitinen, K. (2002), “A dynamic performance measurement system: evidence from small Finnish technology companies". Scandinavian journal of management, Vol. 18 No.1, pp. 65-99.

Laitinen, K (1996), "Framework for small business performance measurement: towards integrated PMS", Paper presented to Vasaa, proceedings of the University of Vasaa.

Lynch, R. and Cross, K. (1991), “Measure Up!” Yardsticks for Continuous Improvement, Blackwell.

Manville, G (2006), "Implementing a balanced scorecard framework in a not for profit SME", Journal of Productivity and Performance Management, Vol.56, No.2, pp. 162-169.

Moultrie, J., Clarkson, P.J. and Probert, D. (2007), "Development of a design audit tool for SMEs", Journal of Product Innovation Management, Vol. 24, pp. 335-68.

Neely, A., Adams, C., and Kennerley, M. (2002), "The Performance Prism": The Scorecard for Measuring and Managing Business Success, Financial Times/Prentice-Hall, London.

Nudurupati, S., Bititci, S., Kumar, V., and Chan, S. (2011), "State of the art literature review on performance measurement". Computers \& Industrial Engineering, Vol.60 No.2, pp. 279-290.

Olve, N-G., Roy, J., and Wetter, M. (1998), Balanced scorecard - yrityksen strateginen ohjausmenetelmä. Porvoo: WSOY. (in Finnish).

Peter W. Management action notes. dti publications.

Stanworth, J. and Purdy, D. (2003), "SME fact and issues, a compilation of current data and issues on UK small and medium sized firms", Labour Financial and Industry Group (LFIG), Westminster Business School.

St-Pierre, J. and Delisle, S. (2006), "An expert diagnosis system for the benchmarking of SMEs" performance", Benchmarking: An International Journal, Vol. 13 No 1/2, pp. 106-19.

Taticchi, P, Cagnazzo, L \& Botarelli, M (2008), "Performance measurement and Management for SMEs: a literature review and a reference framework for PMM design" POMS 19th Annual Conference La Jolla, California, U.S.A, 9-12 May.

Taticchi, P, Tonelli, F. and Luca Cagnazzo. (2010), "Performance measurement and management: a literature review and a research agenda" Measuring Business Excellence Vol. 14 No.1, pp. 4-18.

Van der Wiele, T., Dale, B., Williams, R., Kolb, F., Luzon, D.M., Schmidt, A. and Wallace, M. (1995), "State-of-the-art study on self-assessment", TQM Magazine, Vol. 7 No. 4, pp. 13-17. 